\title{
PENGGUNAAN JENIS BAHASA SERTA INTERAKSI KOMUNITAS PEDAGANG ASONGAN DENGAN WISATAWAN MANCANEGARA DI KAWASAN WISATA PANTAI KUTA, KECAMATAN KUTA, KABUPATEN BADUNG
}

Anak Agung Tirta Putra Wiranata a, 1 , Saptono Nugroho a, 2

1 agungtirta1212015020dpw@gmail.com, 2 snug1976@gmail.com

a Program Studi S1 Destinasi Pariwisata,Fakultas Pariwisata,Universitas Udayana, Jl. Dr. R. Goris, Denpasar, Bali 80232 Indonesia

\section{ABSTRACT}

This field research aims to determine the type of language used by merchant as well their interaction while offering their wares to international tourist. This field research is interesting because, people do not know what kind of language that is often used by merchant when interacting with international tourist while selling their wares. Even with the limitation of language, this phenomenon does not prevent merchant to communicate with international tourist.

The data is analyzed qualitatively. It is collected by structured observation, semi-structured interviews, and documentation study. Whereas, the informants and samples are determined by using Purposive Sampling technique, which was to determine the sample with a certain consideration, which considered to be able to provide the data to the maximum in accordance with the criteria of the research objectives.

The results of the field research states that the type of language used by the merchant in the tourist area of Kuta Beach was pidgin language, because it did not have a native speaker criterion. Pidgin language is a language that does not have native speakers as well as just a means of communication between people - those who do not understand each other. It was seen the merchant on Kuta Beach came from various regions in Indonesia, such as Sumatra, Java, and Bali. It was considered they had been taught since birth with each regional language (mother tongue), not the language that now they use to interact with international tourist. Meanwhile, when the process of interaction between merchant who are offering their wares to international tourist, it was aided with the help of body gestures. This behavior or symbol was being used in the process of interaction between merchant and international tourist, so that them would understand the purpose of the merchant.

Keywords : : Type of Language, Pidgin, Interaction, Merchant, International Tourist, Kuta Beach.

\section{PENDAHULUAN}

Pantai Kuta merupakan salah satu destinasi wisata yang diminati oleh wisatawan penjuru dunia. Kuta berlokasi di bagian Bali Selatan. Kuta dijuluki sebagai destinasi wisata yang tidak pernah tidur, sehingga menjadi kota metropolitannya Pulau Bali. Pantai Kuta juga banyak dikunjungi oleh berbagai jenis wisatawan dari penjuru dunia, dengan begitu masyarakat sekitar akan berkecimpung langsung di dunia pariwisata. Mereka pun membutuhkan bahasa sebagai alat untuk berinteraksi, sebab bahasa adalah suatu simbol bunyi ujaran yang digunakan untuk berkomunikasi. Salah satu mata pencaharian masyarakat yang tinggal di daerah Kuta adalah menjadi pedagang asongan.

Pedagang asongan di Pantai Kuta berjumlah sekitar 1150 orang, \pm 500 orang berasal dari Bali, dan sisanya \pm 650 orang berasal dari Jawa, Lombok, Madura, dan Bandung. Profesi pedagang asongan di Pantai Kuta bermacam-macam, seperti: penjual makanan kecil, minuman kaleng, kepang rambut, hingga asesoris seperti gelang dan kalung. Bermodalkan bahasa asing seadanya serta keberanian, mereka mendekati wisatawan asing dan menjajakan dagangannya dengan bahasa yang unik, seperti "no money !!!, no bargain !!!". Selain menggunakan bahasa asing seadanya, mereka menggunakan suatu simbol untuk berinteraksi, yakni gerak gerik tubuhnya, sehingga fenomena di atas menarik untuk diteliti.

Adapun rumusan masalah pada penelitian ini adalah bagaimana penggunaan jenis bahasa serta interaksi komunitas pedagang asongan dengan wisatawan mancanegara di Kawasan Wisata Pantai Kuta, Kecamatan Kuta, Kabupaten Badung.

\section{KEPUSTAKAAN}

Tinjauan penelitian sebelumnya yang dijadikan referensi adalah jurnal Ilmiah Ilmu Sosial, Fakultas Ilmu Sosial, Universitas Pendidikan Ganesha (2015), oleh N. L. Henny Andayani dan N. Nym Yulianthini, dengan judul Pengembangan Selancar (Surfing) di Kawasan Wisata Pantai Kuta, Kabupaten Badung Melalui Pemberdayaan Masyarakat (Community Based Development).

Deskripsi konsep dan teori yang terdapat dalam jurnal ini meliputi konsep pariwisata (Soekadijo, 1996), daya tarik wisata (UU RI No. 
10 Th. 2009), pedagang asongan (KMRI No. 597/KMK.04/2001), bahasa (Wibowo, 2001), variasi bahasa (Chaer, 2010), pidgin (N.L Sutjiati Beratha, 1999), creole (Brown dan Attardo, 2000), dan teori interaksionisme simbolik (Effendy, 1989).

\section{METODOLOGI PENELITIAN}

Pemilihan Kawasan Wisata Pantai Kuta sebagai lokasi penelitian didasari karena banyak ditemukan pedagang asongan, serta sering dikunjungi oleh berbagai jenis wisatawan dari penjuru dunia. Hal ini yang memicu munculnya ragam jenis bahasa yang terlontar dari perkataan pedagang asongan, yang digunakan untuk berinteraksi dengan wisatawan mancanegara.

Untuk memperjelas dan membatasi permasalahan penelitian ini, maka ruang lingkup penelitian sebagai berikut, yaitu: penggunaan jenis bahasa serta interaksi komunitas pedagang asongan dengan wisatawan mancanegara di kawasan wisata Pantai Kuta. Jenis bahasa yang dimaksud adalah cara atau bahasa yang digunakan oleh pedagang asongan untuk menjual dagangannya kepada wisatawan mancanegara, sedangkan interaksi adalah proses interaksi yang dilakukan antara pedagang asongan dengan wisatawan mancanegara.

Teknik pengumpulan data yang digunakan untuk penelitian ini ada tiga, yaitu: Pertama teknik observasi terstuktur, merupakan teknik yang dilakukan apabila peneliti telah tahu dengan pasti tentang variabel apa yang akan diamati (Sugiyono : 2013). Observasi yang dilakukan pada penelitian ini adalah untuk memperoleh gambaran yang jelas mengenai penggunaan jenis bahasa serta interaksi komunitas pedagang asongan dengan wisatawan mancanegara di kawasan wisata Pantai Kuta. Teknik yang kedua adalah wawancara semi-terstruktur, yaitu tanya jawab bebas dimana peneliti hanya menyusun pertanyaan berupa garis-garis besar permasalahan yang akan ditanyakan (Sugiyono : 2013). Data yang dicari dalam penelitian ini, yaitu mengenai hal yang berkaitan dengan fokus penelitian, yakni penggunaan jenis bahasa serta interaksi komunitas pedagang asongan dengan wisatawan mancanegara di kawasan wisata Pantai Kuta. Teknik yang terakhir adalah studi dokumentasi, yaitu pengumpulan data dari literatur-literatur yang sudah berlalu. Dokumen bisa berbentuk tulisan, gambar, atau karya-karya monumental dari seseorang (Sugiyono : 2013). Contoh dokumen-dokumen tersebut seperti buku-buku mengenai jenis bahasa pidgin dan creole, sehingga dapat melengkapi data-data yang diperlukan dalam penelitian ini.

Penentuan informan dalam penelitian ini menggunakan teknik purposive sampling, yaitu menentukan sampel dengan pertimbangan tertentu yang dipandang dapat memberikan data secara maksimal (Arikunto : 2010). Dalam teknik ini dilakukan wawancara terhadap beberapa pedagang asongan di kawasan wisata Pantai Kuta dikarenakan memiliki pengetahuan mendalam mengenai jenis bahasa yang mereka gunakan saat berinteraksi dengan wisatawan mancanegara dan kepada Ketua Satuan Tugas (SATGAS) Desa Adat Kuta, dikarenakan memiliki pengetahuan mendalam mengenai data karakteristik serta sejarah pedagang asongan di kawasan wisata Pantai Kuta.

Penelitian mengenai penggunaan jenis bahasa serta interaksi komunitas pedagang asongan dengan wisatawan mancanegara di kawasan wisata Pantai Kuta ini menggunakan teknik analisis data deskriptif kualitatif. Menurut Bogdan dan Biklen (1982) dalam Moleong (2012) analisis data kualitatif adalah upaya yang dilakukan dengan jalan bekerja dengan daya, mengorganisasikan data, memilah-milahnya menjadi satuan yang dapat dikelola, mensintesiskannya, mencari dan menemukan pola, menemukan apa yang penting dan apa yang dipelajari, dan memutuskan apa yang dapat diceritakan kepada orang lain.

Hasil data pada penelitian ini meliputi penggunaan jenis bahasa serta interaksi komunitas pedagang asongan dengan wisatawan mancanegara di kawasan wisata Pantai Kuta dengan uraian secara rinci dari data fakta yang diperoleh saat observasi di lapangan.

\section{HASIL DAN PEMBAHASAN}

Pedagang asongan di Pantai Kuta sudah beroperasi dari tahun 1975 hingga sekarang. Awalnya, pedagang asongan dibawah pimpinan dari Pemerintah Daerah (PEMDA) Kuta, mereka menyediakan pengawas bagi pedagang asongan yang sedang berjualan di areal pantai. Pada tahun 1978, PEMDA Kuta merasa kewalahan mengurus pedagang asongan dikarenakan jumlah pedagang asongan yang melunjak hingga \pm 2000 orang, lalu hak megurus pun dipindah tangankan pada Pusat 
Koperasi Angkatan Darat (PUSKOPAD). Setelah 20 tahun berlalu, tepatnya hari reformasi yaitu tahun 1998, PUSKOPAD tidak boleh lagi mengawasi pedagang asongan. Adanya kebijakan yang baru tersebut, PUSKOPAD mengembalikan hak mengurus pedagang asongan ke PEMDA Kuta. Tidak lama kemudian, PEMDA Kuta melepas hak mengurusnya kepada Desa Adat Kuta. Saat dibawah pimpinan Desa Adat Kuta, identitas pedagang asongan berubah yang tadinya persorangan menjadi sebuah komunitas. Nama komunitasnya adalah "Kaula Jaga Wisata Pantai Kuta". Profesi mereka bermacam-macam, mulai dari pedagang minuman dan makanan kecil, penjual accessories, penjual senjata hiasan dinding, jasa surfing, massage, kepang rambut, dan kutek.

Berdasarkan hasil observasi, jenis bahasa yang digunakan pedagang asongan termasuk ke jenis bahasa pidgin, karena bahasa yg digunakan tidak memiliki kriteria "native speaker" (pembicara asli), dimana terdapat pernyataan Native Speaker menurut Bloomfield (1933) dalam buku Language yaitu:

"The first language a human being learns

to speak is his native language; he is a native

speaker of this language"

Dilihat dari pernyataan Bloomfield, pedagang asongan di Pantai Kuta adalah orang dari Indonesia, lebih spesifiknya adalah dari berbagai daerah yang ada di Indonesia. Contohnya adalah seperti Bu Mandi, Bu Lulu, dan $\mathrm{Bu}$ Watis adalah orang Bali, Pak Jega adalah orang Sumatra, dan Pak Ahmad adalah orang Jawa. Tentunya para pedagang ini sejak lahir diajarkan oleh orang tuanya berbahasa daerah masing-masing atau bahasa Indonesia, bukan bahasa yang sekarang mereka gunakan untuk berinteraksi dengan wisatawan mancanegara.

Jika bahasa pidgin ditinjau dengan teori interaksi simbolik, artinya terdapat aksi, interaksi, dan interdependensi dalam konteks tersebut (Pitana : 2005), berikut tabelnya: 


\begin{tabular}{|c|c|c|c|}
\hline No. & Aksi & Interaksi & Interdependensi \\
\hline 1. & $\begin{array}{l}\text { a. Helo, yu wana masas? Jas, } \\
\text { wan tosen paip hanrid } \\
\text { madam. } \\
\text { b. } \quad \begin{array}{l}\text { Koniciwa, masaji des-masaji } \\
\text { des? }\end{array} \\
\text { Sambil memperagakan } \\
\text { tangan memijat punggung. } \\
\text { (gerak gerik pedagang } \\
\text { asongan) }\end{array}$ & $\begin{array}{ll}\text { a. } & \text { Interaksi antara } \\
\text { pedagang asongan } \\
\text { Jasa Massage (Pijat) } \\
\text { dengan wisatawan } \\
\text { mancanegara Inggris. } \\
\text { b. } \\
\text { Interaksi antara } \\
\text { pedagang asongan } \\
\text { Jasa Massage (Pijat) } \\
\text { dengan wisatawan } \\
\text { mancanegara Jepang. }\end{array}$ & $\begin{array}{l}\text { a. Yes, please. } \\
\text { b. } \\
\text { Iie, arrigatou gozaimasu, } \\
\\
\text { tetapi Bu Mandi tidak putus asa } \\
\text { menawarkan jasanya, ia berkata } \\
\text { atatakai jane des berulang dengan } \\
\text { wisatawan mancanegara } \\
\text { tersebut, merasa terusik dengan } \\
\text { cara Bu Mandi dalam } \\
\text { menawarkan jasanya, wisatawan } \\
\text { tersebut marah lalu } \\
\text { meninggalkannya. }\end{array}$ \\
\hline 2. & $\begin{array}{l}\text { Did yu wana serfing bro ?. } \\
\text { Sambil memperagakan tangan } \\
\text { berenang (gerak gerik pedagang } \\
\text { asongan) } \\
\text { Itis cip, jas pour handrid rupiah sir } \\
\text { (Rp. } 400.000 \text {, sambil } \\
\text { memperagakan dengan jari } \\
\text { tangan) en } i \text { wil tic yu tu du it. }\end{array}$ & $\begin{array}{l}\text { Interaksi antara pedagang } \\
\text { asongan pelatihan Surfing } \\
\text { dengan wisatawan inggris. }\end{array}$ & $\begin{array}{l}\text { Yes, I want, how much? (wisatawan } \\
\text { Inggris). } \\
\text { Kemudian wisatawan Inggris tersebut, } \\
\text { langsung berganti pakaian, dan } \\
\text { bermain surfing. } \\
\text { (Wisatawan Inggris tersebut langsung } \\
\text { mau dikarenakan sudah langganan) }\end{array}$ \\
\hline 3. & $\begin{array}{l}\text { Yu wana bloupaip ser? } \\
\text { Jas } 30 \$ \text { US ser, dis bloupaip perais is } \\
\text { mani mani diperen wit ader sir } \\
\text { (sambil menunjuk ke arah toko } \\
\text { cendramata). }\end{array}$ & $\begin{array}{l}\text { Interaksi antara pedagang } \\
\text { asongan senjata hiasan } \\
\text { dengan wisatawan } \\
\text { mancanegara Australia. }\end{array}$ & $\begin{array}{l}\text { Awalnya wisatawan bingung dengan } \\
\text { yang dikatakan Pak Ahmad, kemudian } \\
\text { Pak Ahmad mengeluarkan tulup nya } \\
\text { dari tas, dan wisatawan mancanegara } \\
\text { pun mengerti dan menanyakan } \\
\text { harganya. } \\
\text { Ow, a blowpipe, I like this design, how } \\
\text { much it's? (wisatawan Australia). }\end{array}$ \\
\hline 4. & $\begin{array}{l}\text { Gud morning madam, yu wana } \\
\text { pedikur menikur or maibi yu wana } \\
\text { beraiding yor heir? } \\
\text { Ip yu wana, ip yu laik, kam tu mi } \\
\text { Lulu. }\end{array}$ & $\begin{array}{l}\text { Interaksi antara pedagang } \\
\text { asongan jasa kepang rambut } \\
\text { dan menicure pedicure } \\
\text { (kutek) dengan wisatawan } \\
\text { mancanegara Australia. }\end{array}$ & $\begin{array}{l}\text { Jika wisatawan tidak paham dengan } \\
\text { maksud Bu Lulu, ia langsung } \\
\text { menunjukan koleksi album kutek dan } \\
\text { kepang rambutnya. } \\
\text { I want it, but not now, because I wanna } \\
\text { to look around first (wisatawan } \\
\text { Australia). } \\
\text { Selanjutnya Bu Lulu akan menunggu } \\
\text { wisatawan tersebut, setelah } 30 \text { menit, } \\
\text { Bu Lulu akan mencari dan menanyakan } \\
\text { kembali kepada wisatawan tersebut. }\end{array}$ \\
\hline 5. & $\begin{array}{l}\text { Helo sir / madam, bai dis berakelet } \\
\text { / nekeles. } \\
\text { (sambil melihatkan barang } \\
\text { dagangannya). } \\
\text { Itis cip, jas tuenti tosen rupiah (Rp. } \\
\text { 20.000). } \\
\text { Tengkiu sir / madam gud luking por } \\
\text { yor hen or put, yu ar biutipul / } \\
\text { hansem. }\end{array}$ & $\begin{array}{l}\text { Interaksi antara pedagang } \\
\text { asongan Accessories dengan } \\
\text { wisatawan Australia. }\end{array}$ & $\begin{array}{l}\text { Wow, this bracelet design is unique, how } \\
\text { much it's? (wisatawan Australia), } \\
\text { Hhhmmm, okay I will get this one } \\
\text { (wisatawan Australia), }\end{array}$ \\
\hline nbe & $\begin{array}{l}\text { pidgin terbukti sampai } \\
\text { kan oleh pedagang aso } \\
\text { untuk berinteraksi, dika } \\
\text { ancanegara masih paham } \\
\text { aksud, walaupun pada pr } \\
\text { kit praktek pemaksaan }\end{array}$ & $\begin{array}{l}\text { Deng } \\
\text { interaksi } \\
\text { wisatawan } \\
\text { (ketidak sa } \\
\text { DeVito : } 1 \\
\text { saling mem } \\
\text { cara non- } \\
\text { tubuhnya. }\end{array}$ & $\begin{array}{l}\text { demikian, di dalam proses } \\
\text { tara pedagang asongan dengan } \\
\text { mancanegara terdapat noise } \\
\text { ng pahaman saat berkomunikasi, } \\
\text { 97), sehingga agar kedua pihak } \\
\text { hami, mereka lebih menggunakan } \\
\text { rbal atau dengan gerak gerik }\end{array}$ \\
\hline
\end{tabular}
pedagang. 


\section{SIMPULAN DAN SARAN}

Jadi jenis bahasa yang digunakan oleh pedagang asongan di Pantai Kuta pada saat berinteraksi dengan wisatawan asing adalah bahasa pidgin. Hal ini disebabkan para pedagang tidak memiliki kriteria dari seorang "native speaker" bahasa pidgin (asing). "Native speaker" adalah seorang pembicara asli dari bahasa tertentu, dimana bahasa tersebut mengarah kepada bahasa awal yang dimiliki oleh pembicara tersebut. Pedagang asongan berasal dari berbagai daerah di Indonesia seperti, Sumatra, Jawa, serta Bali, dan tentunya sejak lahir diajarkan oleh orang tuanya berbahasa daerah masing-masing atau bahasa Indonesia, bukan bahasa yang sekarang mereka gunakan untuk berinteraksi dengan wisatawan mancanegara.

Penggunaan bahasa pidgin hingga saat ini masih digunakan karena wisatawan mancanegara mengerti dengan apa yang dimaksud oleh pedagang asongan tersebut, tentunya dengan bantuan gerak gerik tubuh pedagang asongan (non-verbal). Namun beberapa proses interaksi pedagang asongan membuat wisatawan mancanegara merasa terusik, dikarenakan adanya aspek pemaksaan dalam menawarkan dagangannya. Oleh karena itu, gerak gerik pedagang asongan juga mendukung penggunaan bahasa pidgin yang memiliki keterbatasan makna.

Untuk pedagang, disarankan mengikuti pelatihan khusus untuk meningkatkan kualitas dan kemampuan berdagang dalam berinteraksi dengan wisatawan mancanegara. Pelatihan ini dilakukan dengan tujuan meningkatkan kemampuan berdagang mereka, tanpa mengubah jenis bahasa yang digunakan. Pelatihan menekankan pada sistem perdagangan dan tata krama dalam berinteraksi. Hal tersebut akan mendukung penggunaan bahasa pidgin, tanpa harus mengubah ataupun menghilangkan fenomena bahasa yang unik tersebut. Di sisi lain, pelatihan ini juga akan menurunkan praktek pemaksaan yang dilakukan oleh pedagang asongan dalam menawarkan dagangannya, dikarenakan hal tersebut mengganggu kenyamanan wisatawan saat berkunjung ke Pantai Kuta.

Di sisi lainnya, Desa Adat Kuta disarankan untuk mendukung pelaksanaan perdagangan yang dilakukan oleh pedagang asongan tersebut.
Diharapkan dengan adanya dukungan dari pemerintah, dapat menyediakan suatu pelatihan secara berkala. Hal ini akan menunjang proses interaksi antara pedagang asongan saat menjual dagangannya kepada wisatawan mancanegara. Peran pemerintah pun sangat penting di dalam menyediakan tempat pelatihan serta tenaga ahli sebagai instruktur perdagangan, Untuk menghemat biaya, pelatihnya dapat diambil dari anggota SATGAS itu sendiri atau mencari sukarelawan dari tempat lain (mahasiswa).

\section{DAFTAR PUSTAKA}

Andayani, N. L. Henny dan N. Nym Yulianthini. 2012. Pengembangan Selancar (Surfing) di Kawasan Wisata Pantai Kuta, Kabupaten Badung Melalui Pemberdayaan Masyarakat (Community Based Development). Singaraja : Jurusan D3 Perhotelan, Fakultas Ekonomi dan Bisnis, Universitas Pendidikan.

Anonim. Keputusan Menteri Republik Indonesia No. 597/KMK.04/2001.

Anonim. Undang - Undang Kepariwisataan Nomor 10 Tahun 2009.

Arikunto, Suharsimi. 2010. Prosedur Penelitian: Suatu Pendekatan Praktik (Edisi Revisi 2010). Jakarta: PT. RINEKA CIPTA.

Beratha, N.L. Sutjiati. 1999. Variasi Bahasa Inggris pada Kawasan Pariwisata di Bali. Bali : Program Studi Sastra Inggris, Fakultas Sastra, Universitas Udayana.

Bloomfield, L. 1933. Language. New York: Holt Rinehart Winston.

Brown, S. \& Attardo, S. 2000. Understanding Language Structure, Interaction, and Variation. An Introduction to Applied Linguistics and Sociolinguistics for Nonspecialists. Michigan: The University of Michigan Press.

Chaer, Abdul dan Leonie Agustina. 2010. Sosiolinguistik: Perkenalan Awal. Jakarta: Rineka Cipta.

DeVito, Joseph A. 1997. Komunikasi Antarmanusia. Jakarta : Professional Books.

Effendy, Onong Uchjana. 1989. Kamus Komunikasi. Bandung: Mandar Maju.

Moleong, Lexy J. 2012. Metodologi Penelitian Kualitatif. Bandung: PT. Remaja Rosdakarya.

Pitana, I Gde dan Putu G. Gayatri. 2005. Sosiologi Pariwisata, Kajian Sosiologis terhadap Struktur, Sistem, dan Dampak-Dampak Pariwisata. Yogyakarta: ANDI.

Soekadijo, R. G. 1996. Anatomi pariwisata: memahami pariwisata sebagai "systemic linkage. Gramedia Pustaka Utama.

Sugiyono. 2013. Metode Penelitian Kuantitatif, Kualitatif, dan $R \& D$ (Research and Development). Bandung: Alfabeta.

Wibowo, Wahyu. 2001. Menajemen bahasa: pengorganisasian karangan pragmatik dalam Bahasa Indonesia untuk mahasiswa dan praktis bisnis. Jakarta: Gramedia Pustaka Utama. 